\title{
Bilateral hydrosalpinges masquerading as ovarian cancer: a late complication of microwave endometrial ablation: a case report and literature review
}

\author{
Gbolahan Somoye • Stuart Thomas • Gail Fullerton • \\ David Parkin
}

Received: 14 July 2009 /Accepted: 7 September 2009 /Published online: 24 September 2009

(C) Springer-Verlag 2009

\begin{abstract}
We report on a late presentation of bilateral hydrosalpinges 2 years following microwave endometrial ablation. The patient was reviewed in the Gynaecological Oncology Centre on account of a raised cancer antigen 125 (CA125) and suspicious appearances on ultrasound and computed tomography. Benign tubal masses should be considered amongst the differential diagnosis in women presenting with adnexal masses and a raised CA125 following endometrial ablative procedures.
\end{abstract}

Keywords Microwave endometrial ablation · Complication

\section{Introduction}

A 47-year old multiparous lady presented to a district general hospital with a 10-month history of progressively worsening left lower abdominal pain. There were no associated urinary or bowel symptoms. Twenty months prior to presentation, she had undergone microwave endometrial ablation (MEA) for dysfunctional uterine bleeding. She had been amenorrhoeic since that time. Her cervical cytology was up to date and normal. She had no other relevant medical history. Family history included a

\footnotetext{
G. Somoye $(\bowtie) \cdot G$. Fullerton $\cdot$ D. Parkin

Department Gynaecological Oncology, Ward 43,

Aberdeen Royal Infirmary,

Foresterhill,

Aberdeen AB25 2ZN, UK

e-mail: g.somoye@nhs.net

S. Thomas

Department of Pathology, Aberdeen Royal Infirmary,

Foresterhill,

Aberdeen AB25 2ZN, UK
}

maternal history of breast cancer. Abdominal examination revealed a soft abdomen with a firm palpable mass in the suprapubic region and tenderness in the left iliac fossa. Bimanual examination revealed a slightly bulky uterus, normal right adnexa and a mass in the left adnexa indistinct from the uterus and bulging into the left vaginal fornix and pouch of Douglas.

Transabdominal ultrasound scanning (USS) revealed a $7 \times 7 \times 5-\mathrm{cm}$ irregular mainly loculated cystic mass with solid components in the left adnexa. Another $3.7 \mathrm{~cm}$ cystic area was noted, adjacent to the mass. The uterus was bulky, with some fluid and low level echoes within the endometrial canal. The endometrial canal measured $19 \mathrm{~mm}$. There was no free fluid in abdomen. A cancer antigen 125 (CA125) was raised at $295.9 \mathrm{U} / \mathrm{ml}(0-35)$. This gave a risk of malignancy index (RMI) of 888, above the threshold value of 200 beyond which may be suggestive of malignancy [1]. Although a raised Ca125 may be associated with benign conditions, the elevated RMI raised the suspicion of an ovarian malignancy. The Scottish Intercollegiate Guidelines Network (SIGN) recommends the use of the RMI as the standard method of choice for predicting the likelihood of malignancy in an ovarian mass [2]. Indeed, a population-based study in North East Scotland revealed a $94 \%$ sensitivity of the RMI for diagnosing malignant ovarian disease [3]. In view of the raised $\mathrm{Ca} 125$ and suspicious appearances on USS, a computed tomography (CT) was requested. CT showed a $5.3 \times 7.3 \times 6.4-\mathrm{cm}$ cystic lesion with a solid component within the left adnexa and a $5.4 \times 5.2 \times 6.4$ $\mathrm{cm}$ multiloculated lesion in the right adnexa. The uterus appeared bulky with a distended cavity with low attenuation suggestive of fluid within the endometrial canal. A 7-mm mesenteric node was noted with no other significant lymphadenopathy. There were no other abnormalities. A working diagnosis of ovarian cancer was made. 
She was discussed at the regional Gynaecological Oncology Multidisciplinary Team (MDT) meeting. Ovarian cancer was thought to be the likely cause, but similarities to a previous case of haematosalpinges following transcervical endometrial resection (TCRE) was noted [4]. Although laparoscopic surgery may be instrumental in staging and assessing the extent and resectibility of disease in ovarian cancer, limitations to laparoscopy include incomplete staging, tumour dissemination and port site metastasis [5]. A midline laparotomy enables a systematic exploration of all intraabdominal surfaces and viscera [2]. Thus, in keeping with national guidelines [2], she was scheduled for a staging laparotomy and probable total abdominal hysterectomy and bilateral salpingoophorectomy (TAH BSO) at the Regional Gynaecological Cancer Centre.

At laparotomy, the findings were a bulky uterus, large bilateral swollen fallopian tubes embedded in the pouch of Douglas that were densely adherent to the posterior aspect of the uterus. The ovaries appeared normal, and there was no clinical evidence of malignancy. TAH BSO and omental biopsy was performed after obtaining peritoneal cytology. There were no other abnormalities found at laparotomy. She made satisfactory postoperative recovery and was discharged home on the sixth postoperative day.

Macroscopic histopathological examination showed markedly distended fallopian tubes and uterine cavity (Fig. 1). On microscopy within the fallopian tubes, there was evidence of fibrosis of the plecae and wall with an associated acute inflammatory infiltrate within the superficial aspects of the luminal wall (Fig. 2). Features were those of

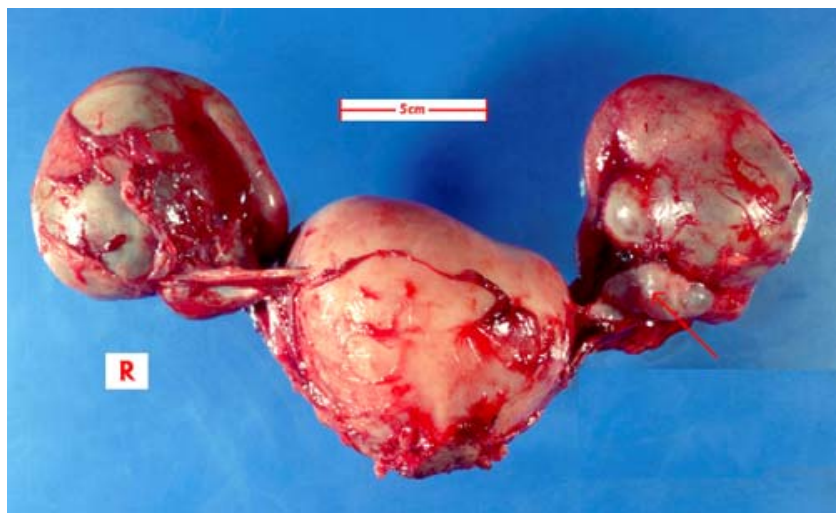

Fig. 1 Gross anatomy: subtotal hysterectomy and bilateral salpingooopherectomy specimen. Received was a subtotal hysterectomy and bilateral salpingo-oopherectomy specimen. The uterine body was distended by a dark, brown fluid reminiscent of altered blood. On opening, the uterine wall was thickened and contained pale nodular areas of up to $12 \mathrm{~mm}$ in greatest diameter. Both fallopian tubes were distended by a similar fluid. The left ovary (arrow) appeared cystic, with individual cysts measuring up to $15 \mathrm{~mm}$ in greatest diameter. The right ovary was not identifiable and was believed by fibrosis. Subsequent histology showed that the pale nodular areas within the myometrium were benign, part hyalinised, leiomyomas. The ovarian cysts were benign follicular cysts

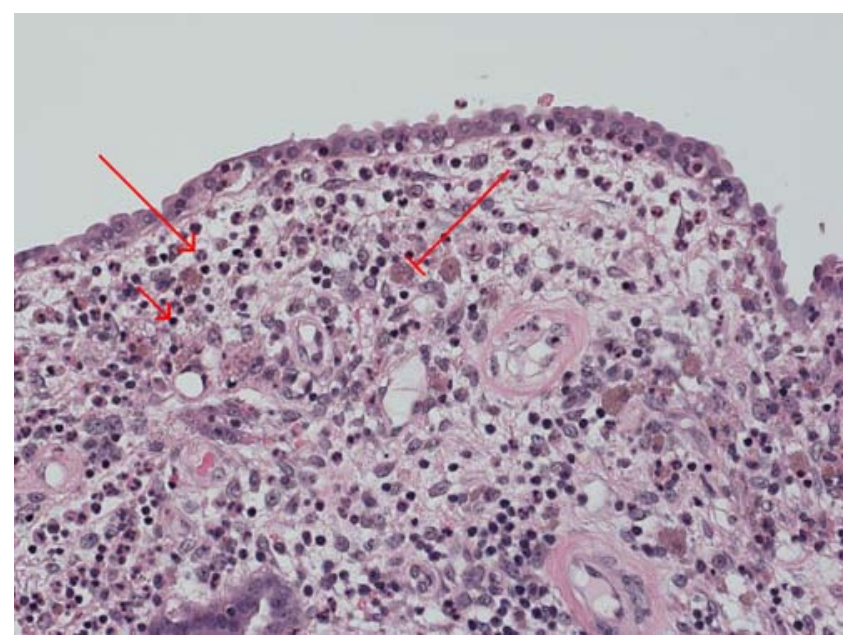

Fig. 2 Histopathology, fallopian tube (H\&E; $\times 400$ magnification). Cross-section of fallopian tube showing an acute on chronic salpingitis, with both acute inflammatory (neutrophils; long arrow) and chronic inflammatory cells (lymphocytes; short arrow). There is a mild background fibrosis, with evidence of previous haemorrhage (pigment laden macrophages; blunt ended arrow)

an acute on chronic salpingitis and acute on chronic endometritis (Figs. 2 and 3).

\section{Discussion}

Heavy menstrual bleeding is a common complaint encountered in the gynaecological outpatient. Hysterectomy has traditionally been the treatment for women with heavy periods, refractory to medical treatment. Minimal access endometrial ablative techniques were introduced as less invasive methods, with reduced morbidity and quicker recovery time in comparison to major surgery [6].

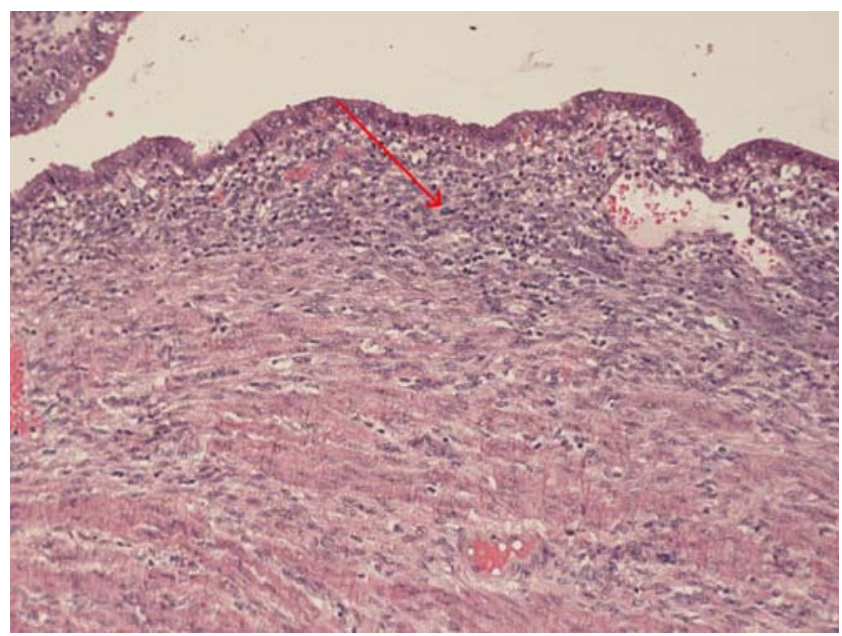

Fig. 3 Histopathology, endometrium (H\&E; $\times 200$ magnification). Cross-section of endometrium showing an active acute on chronic inflammation with the occasion plasma cell identified (arrow). The endometrium was otherwise inactive 
MEA is an effective treatment for dysfunctional uterine bleeding (DUB). It is a second generation endometrial ablative technique that employs the use of microwaves at a fixed frequency of $9.2 \mathrm{GHz}$ to destroy the endometrial lining.

The efficacy and beneficial effects of MEA have long been established in several randomised controlled trials (RCT) with follow-up to at least 10 years [7-9]. Further studies have demonstrated an improved cost effectiveness of second generation ablative techniques for DUB in comparison to first generation options and hysterectomy $[10,11]$.

Thermal effects of MEA are associated with damage and tissue injury to the endometrial and superficial myometrial layer with recruitment of inflammatory cells and subsequent inflammation that constitutes the ablative effect [12]. Though the depth of thermal damage is safe and controllable, it has been associated with occlusion of the upper genital tract. Tawfeek et al. investigated 35 women post MEA with hysterosalpingogram 3 months later to determine the incidence of upper genital tract (tubal) occlusion. They demonstrated an $85.7 \%(n=30)$ of complete upper genital tract occlusion [13]. There have been no reports of cervical stenosis following MEA.

Various complications have been reported in the literature. Parkin reported on a prospective observational study describing all complications associated with MEA accrued from data obtained from 13 hospitals in the United Kingdom and Canada [14]. Of a total of 1,433 MEA procedures performed, there was one major complication, a bowel perforation that required a small bowel resection. Fourteen women were readmitted with a clinical diagnosis of endometritis, though this was seldom confirmed with bacteriological culture.

Milligan et al., in a case series, investigated 173 patient experiences in the first 3 months following MEA [15]. Commonly reported symptoms were immediate postoperative pain $(61 \%)$, abdominal pain in the following weeks $(75 \%)$, vaginal discharge (87\%), vaginal bleeding (74\%) and vaginal dryness. The reported symptoms were mild with no major complications.

Cooper et al. reported on the complication rates of MEA in a RCT [7]. Of 129 women, there were 11 cases of equipment failure, a case of blunt perforation and four minor secondary haemorrhages. Trends of complications among various endometrial ablation devices reported to the Food and Drug Administration's Manufacturer and User Facility Device Experience (MAUDE) database were reviewed in the United States [16]. For the time period January 2003 to December 2006, no hydro or haematosalpinges were reported. There is a solitary report of a pelvic abscess following MEA reported in the literature [17].
We do not have specific clinical or microbiological evidence of prior infection to suggest pyosalpinges. To our knowledge, this is the first reported case of bilateral hydrosalpinges following MEA. We postulate that the pathogenesis may have resulted from ascending infection and chronic inflammation secondary to endometrial ablation, based upon the histopathological evidence. Macroscopic examination at surgery and pathological examination of the specimen revealed a distended uterine cavity, suggesting that the lower uterus/cervical canal was occluded preventing the drainage of tubal and uterine fluid. Haematometra and consequential haematosalpinges were considered as differential diagnoses.

The Ca125 is a useful tool for the triage and prediction of ovarian cancer preoperatively [18]. It was raised both in this case and a previous case of haematosalpinges 5 years after a TCRE we previously reported [3]. In that case, it was only after extensive surgery that the benign nature of the pathology was realised. In a woman with a bilateral adnexal masses and a raised CA125 following an endometrial ablation or resection, benign tubal masses should be included in the differential diagnosis.

Conflict of interest There is no actual or potential conflict of interest in relation to this article.

\section{References}

1. Jacobs I, Oram D, Fairbanks J, Turner J, Frost C, Grudzinskas JG (1990) A risk of malignancy index incorporating CA 125, ultrasound and menopausal status for the accurate preoperative diagnosis of ovarian cancer. BJOG 10:922-929

2. Scottish Intercollegiate Guidelines Network (2003) 75 epithelial ovarian cancer, a national clinical guideline www.sign.ac.uk

3. Harry VN, Narayansingh GV, Parkin DE (2009) The risk of malignancy index for ovarian tumours in Northeast Scotland-a population based study. Scott Med J 54:21-23

4. Narayansingh GV, Parkin DE, Dillon P (1999) Gross bilateral haematosalpinges presenting 5 years following endometrial resection. Gynaecol Endosc 8:55-57

5. Angioli R, Muzii L, Battista C, Terranova C, Ornozi I, Sereni MI, De Oronzo MA, Damiani P, Collettini F, Graziano M, Benedetti Panici P (2009) The role of laparoscopy in ovarian carcinoma. Minerva Ginecol 61:35-43

6. National Institute for Clinical Excellence (2003) Microwave endometrial ablation Interventional Procedure Guidance 7. National Institute for Clinical Excellence, London

7. Cooper KG, Bain C, Parkin DE (1999) Comparison of microwave endometrial ablation and transcervical resection of the endometrium for treatment of heavy menstrual loss: a randomized trial. Lancet 354:1859-1863

8. Sambrook AM, Bain C, Parkin DE, Cooper KG (2009) A randomized comparison of microwave endometrial ablation with transcervical resection of the endometrium: follow up at a minimum of 10 years. BJOG 116:1033-1037

9. Cooper JM, Anderson TL, Fortin CA, Jack SA, Plentl MB (2004) Microwave endometrial ablation vs. rollerball electroablation for 
menorrhagia: a multicenter randomized trial. J Am Assoc Gynecol Laparosc 11:394-403

10. Garside R, Stein K, Wyatt K, Round A, Pitt M (2004) A cost-utility analysis of microwave and thermal balloon endometrial ablation techniques for the treatment of heavy menstrual bleeding. BJOG 111:1103-1114

11. Garside R, Stein K, Wyatt K, Round A, Price A (2004) The effectiveness and cost-effectiveness of microwave and thermal balloon endometrial ablation for heavy menstrual bleeding: a systematic review and economic modelling. Health Technol Assess 8(3):1-155

12. Wang HL, Dong XY, Wang LL, Yang YF, Han CX (2007) Tissue injury observation caused by thermal effects of microwave endometrial ablation. Zhonghua Fu Chan Ke Za Zhi 42:102-106

13. Tawfeek S, Sholapurkar S, Sharp N (2006) Incidence of upper genital tract occlusion following microwave endometrial ablation (MEA). BJOG 113:958-960
14. Parkin DE (2000) Microwave endometrial ablation MEA (trademark). A safe technique? Complication data from a prospective series of 1400 cases. Gynaecol Endosc 9:385-388

15. Milligan MP, Etokowo G, Kanumuru S, Mannifold N (2002) Microwave endometrial ablation: patients' experiences in the first 3 months following treatment. J Obstet Gynaecol 2:201204

16. Della Badia C, Nyirjesy P, Atogho A (2007) Endometrial ablation devices: review of a manufacturer and user facility device experience database. J Minim Invasive Gynecol 4:436441

17. Das S, Kirwan J, Drakeley AJ, Kingsland CR (2005) Pelvic abscess following microwave endometrial ablation. BJOG 112:118-119

18. Rosenthal AN, Jacobs IJ (1998) The role of Ca 125 in screening for ovarian cancer. Int J Biol Markers 13:216-220 